\title{
Evaluation of influencing factors on the adaptability of ICD completion technology
}

\author{
Guohui Zhang ${ }^{1}{ }^{*}$, Liangchuan Li ${ }^{1}$, Rongchen ${ }^{1}$, Pengwang ${ }^{1}$, Guowen Zhang ${ }^{1}$, and Jiewen Sun ${ }^{1}$ \\ ${ }^{1}$ PetroChina Research Institute of Petroleum Exploration \& Development, Beijing 100083, China
}

\begin{abstract}
After years of research and practice, ICD well completion technology has become a relatively mature completion technology, and has been successfully applied in hundreds of horizontal Wells abroad. However, due to many factors affecting ICD effect, mature evaluation methods have not been completely established. At present, the main index of ICD water control development effect is to balance inflow profile and inhibit water production, and the evaluation factors involve reservoir, process and equipment structure. This paper summarizes the factors influencing the effects of ICD, using orthogonal experiment design method to carry on the comprehensive evaluation, and puts forward the corresponding Suggestions
\end{abstract}

\section{Introduction}

Compared with vertical wells, horizontal wells can effectively increase the drainage area, reservoir fluid seepage resistance reduction, enhance oil recovery, improve oil field production, at present have been widely used in oilfield development. However, horizontal well with the client and toe the pressure differences of the fluid along the horizontal wellbore inflow inhomogeneity, lead to horizontal well early water breakthrough, output fell sharply after water breakthrough, the heterogeneity of reservoir and development of natural cracks will further aggravate the inflow profile irregularity. In order to regulate the Inflow profile of horizontal wells and ensure the long-term stable production of wells, the technical personnel has introduced the Inflow Control valve ICD (Inflow Control Device) on the completion string. It provides an effective way for horizontal well water control [1]. Field practice has shown that optimized ICD completions reduce annular flow, reduce the risk of local screen blockage, enhance the stability of ICD completions, and achieve the goal of oil stabilization and water control. However, in practice, it is found that there are many factors affecting ICD effect, and mature evaluation methods have not been completely established. Therefore, it is necessary to evaluate the influencing factors of ICD and formulate corresponding technical countermeasures to improve the application effect of ICD. ${ }^{[2-4]}$

\section{The influencing factors of well completion technology of ICD adaptability}

The main index in the evaluation of water control in the ICD development effect is balanced inflow profile, inhibiting water rate, well completion technology of ICD adaptability evaluation factors mainly from the inflow, outflow and inflow control devices are analyzed ${ }^{[5-8]}$. The inflow part is mainly related to the characteristics of the reservoir itself, including reservoir type, reservoir thickness, reservoir heterogeneity, permeability, $\mathrm{k}_{\mathrm{V}} / \mathrm{k}_{\mathrm{h}}$ and the accuracy of reservoir description. The outflow is mainly due to process and equipment factors, including horizontal section length, number of stages, base pipe size, reservoir $\mathrm{P}_{\mathrm{ICD}} / \mathrm{P}_{0}$ inflow control equipment, and ICD type and stability. ${ }^{[9-11]}$

\section{Performance factors}

ICD completion inflow control equipment is closely related to the design of the manufacturer. In particular, most of the ICD structural design principles cannot be changed. This paper only provides some constructive suggestions

\subsection{The influence of ICD structure design}

Screen completion technology can't prevent formation sand particles into the ICD, its kinetic energy is very large, if the sand fluid will be long-term to erosion of ICD device, the erosion effect can accelerate the ICD equipment damage. Its control parameters include particle content and size, the speed of the fluid. Therefore, ICD structure design is mainly related to fluid velocity, and particle size and particle content cannot be changed.

Current ICD types are designed to adjust the fluid production profile by generating an additional pressure drop. There are two main types of spiral type (friction type) and nozzle/orifice type (throttling type). Spiral ICD, also known as friction ICD, realizes profile control by generating friction and additional pressure drop on the device surface itself. The most important feature of this

\footnotetext{
$\overline{{ }^{*} \text { Corresponding author: zhangguohui@ }}$ petrochina.com.cn 
type of ICD is that it requires a larger flow area and a smaller flow rate to generate pressure drop, which reduces the probability of erosion or blockage. The disadvantage is that its viscosity sensitivity is higher, resulting in the liquidity preference of water first, water in advance. Orifice ICD is also called throttle ICD. Its principle is to reduce the area of fluid flow to produce additional pressure drop, that is to say, fluid flow from a large space to a small space to produce flow resistance. Its design structure is simple, the corresponding structure parameters need to optimize the time is short, the viscosity of the fluid itself is less sensitive. The disadvantage is that when the flow rate of the fluid itself is high, erosion is more likely to occur and damage the ICD control equipment. In addition, it is more likely to cause the plugging of small holes when the mud is drained back.

Therefore, if low viscosity sensitivity and low probability of erosion and blockage can be realized, it is the ideal ICD structure characteristics. In other words, during the design of ICD structure, it is necessary to ensure that the flow velocity through the orifice is lower than the critical velocity when the erosion occurs and the mechanism of pressure drop is preferred.

\subsection{The influence of reservoir characteristics on the effect}

The influence of ICD technology adaptability on reservoir heterogeneity, reservoir thickness, permeability and $\mathrm{k}_{\mathrm{V}} / \mathrm{k}_{\mathrm{h}}$ was discussed.

\subsubsection{Effect of permeability variation coefficient}

Heterogeneous reservoir is an important factor affecting the adaptability of ICD completion technology. Through the analysis of the simulation results, the following viewpoints exist:

(a) When the coefficient of variation of permeability is equal to 0 , the completion profile control effect of ICD is poor, and the additional pressure drop generated will only increase the seepage resistance and fail to achieve the profile control effect; When the coefficient of variation of permeability is equal to 0 , the completion profile control effect of ICD is poor, and the additional pressure drop generated will only increase the seepage resistance and fail to achieve the profile control effect; while in the heterogeneous reservoir, the well completion technology of ICD can adjust the flow profile of different level of equilibrium level, so its strong adaptability in the heterogeneous reservoir.

(b) The degree of permeability heterogeneity was positively correlated with the difference in the coefficient of variation of inflow profiles between ICD and conventional completions. In other words, the greater the permeability variation coefficient, the greater the completion advantage of ICD, the greater the degree of adjustment to the inflow profile, and the better profile control and water control effect.

(c) There was also a positive correlation between permeability heterogeneity and water production reduction, indicating that ICD completion technology is more adaptable to reservoirs with higher heterogeneity

(d) In reservoirs with low permeability heterogeneity, such as reservoirs less than 0.1 , ICD completions are not recommended because of the inherent risk and cost of ICD completions. It is not easy to use in case of poor profile control effect.

\subsubsection{Average permeability on the effect}

According to the calculation formula of ICD pressure drop the flow rate has a great influence on the additional pressure difference generated by ICD completion technology, and the flow rate is mainly controlled by the average formation permeability. Therefore, the average formation permeability should be regarded as an important factor to evaluate the adaptability of ICD completion technology.

In the case of constant pressure with coefficient of variation of 0.6 and fixed production with coefficient of variation of 0.2 , the formation average permeability is set at $10 \mathrm{mD}, 50 \mathrm{mD}, 150 \mathrm{mD}, 300 \mathrm{mD}, 500 \mathrm{mD}, 800 \mathrm{mD}$ and $1000 \mathrm{mD}$ for simulation, and the following conclusions are drawn:

(1) The effect of ICD in low permeability reservoirs under constant pressure production conditions is poor. If the permeability is less than $150 \mathrm{mD}$, both the inflow profile and the relative reduction in water production will not change much compared with conventional completions, and the purpose of better profile control and water control cannot be achieved. With a certain production pressure difference, the profile control and water control ability of ICD completion increases with the increase of the formation average permeability. There is also a positive correlation between the formation average permeability and the relative reduction in water production, indicating that the ICD completion technology is more adaptable to the formation with higher formation average permeability. Considering the cost of ICD completion technology, domestic and foreign production practices and the geological characteristics of reservoirs in China, it is recommended to use ICD completion technology less often in low permeability reservoirs (less than $150 \mathrm{mD}$ ).(2) In the case of fixed production, compared with conventional completion technology, ICD completion increases with the increase of the average reservoir permeability, and the difference of inflow profile variation coefficient also increases, which enhances profile control and water control ability, and has better adaptability. ICD completion technology is not ideal for profile control in reservoirs with an average formation permeability below $150 \mathrm{mD}$. Therefore, ICD completion technology is not recommended for reservoirs with an average formation permeability below $150 \mathrm{mD}$.

\subsubsection{The effect of reservoir thickness}

Based on the mechanism model, the coefficient of variation was assumed to be 0.2 and the formation average permeability was $300 \mathrm{mD}$. The production of screen and ICD completions with different reservoir thicknesses was simulated at $\mathrm{Q}=50 \mathrm{~m}^{3} / \mathrm{d}$. Reservoir thicknesses were set at 
$10 \mathrm{~m}, 40 \mathrm{~m}, 60 \mathrm{~m}, 70 \mathrm{~m}, 100 \mathrm{~m}$, and $120 \mathrm{~m}$. The conclusions are as follows:

The development results of ICD completion technology have a good correlation with reservoir thickness. The greater the reservoir thickness, the better the development results, and the stronger the adaptability of ICD completion technology. With the increase of reservoir thickness, ICD completion technology reduces the maximum pressure drop, reduces profile control and water control ability, and becomes more adaptable.

\subsubsection{Ratio of vertical to horizontal permeability}

$\mathrm{k}_{\mathrm{V}} / \mathrm{k}_{\mathrm{h}}$ can qualitatively characterize the formation heterogeneity, and it will also have an impact on the inflow profile. Set parameter $\mathrm{K}=300 \mathrm{md}, \mathrm{V}=0.5,40, \mathrm{Q}=50 \mathrm{~m}^{3}$ $/ \mathrm{h}$, respectively for $\mathrm{kv} / \mathrm{kh}$ value of $0.1,0.2,0.3,0.4,0.5$, through simulation screen completion and ICD completion the impact on the production situation of size, specific results is the production index increases with increase of $\mathrm{k}_{\mathrm{v}} / \mathrm{k}_{\mathrm{h}}$, ICD's biggest pressure drop decrease with the increase of $\mathrm{k}_{\mathrm{v}} / \mathrm{k}_{\mathrm{h}}$ value, there is a lower risk of ICD erosion occurred at the same time, profile control and enhancing the ability of water control, the adaptability of well completion technology of ICD.

\subsection{The effect of process factors on ICD application}

The main factors influencing ICD completion technology include the ratio of reservoir pressure drop to ICD pressure drop, the number and length of horizontal sections, and the size of base pipe. Let's discuss them one by one.

As the ratio between ICD pressure drop and reservoir pressure drop increases, the ratio of additional pressure drop to total pressure drop generated by ICD gradually increases, and its influence on inflow profile increases, thus making it more adaptable. In other words, with the increase of reservoir PPICD value, the difference of inflow profile variation coefficient will be larger.

However, if the ratio is much greater than 1 , its influence on the production index is greater. Practice shows that when the ratio is equal to 1 , the development effect of ICD completion technology is the best.

\subsubsection{Influence of horizontal segment length on ICD application effect}

The length of the horizontal segment directly affects the heel-toe effect. By changing the length of the horizontal well section, the development of conventional and ICD completions was simulated at $400 \mathrm{~m}, 600 \mathrm{~m}, 800 \mathrm{~m}, 1000 \mathrm{~m}$ and $1500 \mathrm{~m}$, and the results were as follows.

The difference of variation coefficient between horizontal section length and inflow profile basically shows a linear increasing relationship, that is to say, with the increase of horizontal section length, the profile control and water control ability of ICD completion will increase and its adaptability will be enhanced. At the same time, the horizontal section length and the decrease of water production also increased, while the decrease of oil production decreased, indicating that the length of horizontal well has a good positive correlation with the technical adaptability of ICD completion. Because other conditions are certain, the length of the horizontal section directly affects the heel-toe effect. The larger the length, the greater the pressure difference between the heel-toe end and the toe end, and the more obvious the heel-toe effect. The ICD completion technology is more adaptable.

\subsubsection{The effect of base tube diameter on ICD application}

Similar to the length of the horizontal well section, the diameter of the base pipe directly affects the "heel-toe effect". We also set the inner diameters of the base pipe as $47.625 \mathrm{~mm}, 63.5 \mathrm{~mm}, 88.9 \mathrm{~mm}, 114.3 \mathrm{~mm}$, and $152.4 \mathrm{~mm}$ respectively to study the influence of screen completion and ICD completion on the development effect. The results are as follows:

(a) Base tube diameter has an important influence on ICD completion. The larger the base tube diameter is, the smaller the difference of inflow profile variation coefficient is, and the base tube diameter is negatively correlated with ICD completion profile control and water control ability. The smaller the base tube diameter is, the better the ICD completion technology adaptability is.

(b) The relative reduction of water production and oil production decreased with the increase of the base pipe diameter. If the base pipe diameter was relatively small, the relative reduction of water production decreased faster, and the decrease trend of oil production decreased slowly, indicating that the base pipe diameter was negatively correlated with the ICD completion technology adaptability. The reason is that with the decrease of the diameter of the base tube, the frictional resistance generated by the fluid flowing through the base tube increases. According to the formula, the frictional pressure drop is proportional to the 5 th power of the diameter of the base tube. At this time, the pressure difference between the heel end and the toe end increases, and the "heel effect" becomes more obvious and its adaptability is enhanced.

\subsubsection{The effect of the number of segments on the application of ICD}

The number of sections is also an important factor affecting the development effect of ICD completion technology. We simulated the specific production conditions of screen and ICD completions with different stages, and set stages $1,3,5,7$, and 9 to obtain the following results:

(a) With the increase of the number of sections, the variation coefficient of inflow profile of ICD completion technology showed a decreasing trend, that is, the more the number of sections in ICD completion, the more balanced the inflow profile, and the stronger the adaptability of ICD completion technology.

(b) If the horizontal well is not segmented, the ICD completion will have the same inflow profile shape as the conventional completion, which will fail to achieve profile control and water control. The reason is that the horizontal 
well is not segmenting, the fluid in the high permeability section can pass through the annulus and the attached pressure drops are small ICD, the high permeability section is still the main fluid producing section, and its profile control and water control effect is poor. When the number of segments increases, the permeability range becomes smaller, and interflow basically does not occur. As a result, the flow resistance of the fluid in the high permeability section increases, which is more conducive to the adjustment of the inflow profile, and the adaptability is significantly enhanced.

\section{Sensitivity analysis of influencing factors on ICD completion adaptability}

The above analysis shows that different parameters have different degrees of influence on the ICD completion technology adaptability. Some have important effects while others have little effects. Therefore, how to determine the weight of each parameter is the issue to be discussed in this section. Based on the single factor impact analysis and orthogonal design experiment, the orthogonal sensitivity analysis of the factors that affect the adaptability of ICD completion technology was carried out to determine the weight of each factor.

\subsection{Orthogonal experimental design}

The production practice at home and abroad shows that the process factors affecting ICD completion technology mainly include the ratio of reservoir pressure drop to ICD pressure drop, the number and length of horizontal sections, and the size of base pipe. Let's discuss them one by one.

The basic principle of orthogonal experiment analysis is probability theory and mathematical statistics method. It carries out multi-factor experiment through scientific arrangement, calculates a set of normalized orthogonal table, carries out multi-factor orthogonal experiment according to its balanced dispersion and neat comparison, and finally analyzes the results statistically.

In the process of single factor analysis, it is found that the main factors affecting the profile control and water control ability of ICD completion technology are reservoir factors and process factors. Compared with the variation coefficient of inflow profile of screen completion, the difference of variation coefficient of inflow profile is taken as the evaluation index of sensitivity analysis, namely, the orthogonal test results. The consideration factors are shown in the following table (Table 1-3).

Table 1. Evaluation parameter orthogonal design table

\begin{tabular}{|c|c|c|c|c|}
\hline $\begin{array}{c}\text { Factor } \\
\text { name }\end{array}$ & $\begin{array}{c}\text { Horizontal } \\
\text { section } \\
\text { length } \\
(\mathrm{m})\end{array}$ & $\begin{array}{c}\text { Base tube } \\
\text { diameter } \\
(\mathrm{mm})\end{array}$ & $\mathrm{P}_{\mathrm{ICD}} / \mathrm{P}_{0}$ & $\begin{array}{c}\text { Number of } \\
\text { segments }\end{array}$ \\
\hline 1 & 400 & 47.6 & 5 & 1 \\
\hline 2 & 600 & 63.5 & 10 & 5 \\
\hline
\end{tabular}

\begin{tabular}{|c|c|c|c|c|}
\hline 3 & 800 & 88.9 & 50 & 7 \\
\hline 4 & 1000 & 152.4 & 100 & 9 \\
\hline $\begin{array}{c}\text { Factor } \\
\text { name }\end{array}$ & $\begin{array}{c}\text { Permeability } \\
(\mathrm{md})\end{array}$ & $\begin{array}{c}\text { Reservoir } \\
\text { thickness(m) }\end{array}$ & Kv/kh & $\begin{array}{c}\text { Coefficient } \\
\text { of } \\
\text { variation }\end{array}$ \\
\hline 1 & 10 & 10 & 0.1 & 0 \\
\hline 2 & 50 & 40 & 0.2 & 0.2 \\
\hline 3 & 300 & 70 & 0.3 & 0.4 \\
\hline 4 & 500 & 100 & 0.4 & 0.6 \\
\hline
\end{tabular}

When there are many influencing factors, the analysis error brightness will increase. Considering the independence of reservoir parameters and process parameters, orthogonal tests will be conducted respectively, and the specific design is as follows.

Table 2. Orthogonal design table of process parameters

\begin{tabular}{|c|c|c|c|c|c|}
\hline Factor & $\begin{array}{l}\text { Horizo } \\
\text { ntal } \\
\text { section } \\
\text { length } \\
(\mathrm{m})\end{array}$ & $\begin{array}{c}\text { Base } \\
\text { tube } \\
\text { diameter } \\
(\mathrm{mm})\end{array}$ & $\mathrm{P}_{\mathrm{ICD}} / \mathrm{P}_{0}$ & $\begin{array}{l}\text { Number } \\
\text { of } \\
\text { segments }\end{array}$ & $\begin{array}{l}\text { The test } \\
\text { results }\end{array}$ \\
\hline 1 & 400 & 47.6 & 5 & 1 & 0.00109 \\
\hline 2 & 400 & 63.5 & 10 & 5 & 0.07568 \\
\hline 3 & 400 & 88.9 & 50 & 7 & 0.50171 \\
\hline 4 & 400 & 152.4 & 100 & 9 & 0.49952 \\
\hline 5 & 600 & 47.6 & 5 & 1 & 0.58412 \\
\hline 6 & 600 & 63.5 & 10 & 5 & 0.07365 \\
\hline 7 & 600 & 88.9 & 50 & 7 & 0.00609 \\
\hline 8 & 600 & 152.4 & 100 & 9 & 0.25017 \\
\hline 9 & 800 & 47.6 & 5 & 1 & 0.36123 \\
\hline 10 & 800 & 63.5 & 10 & 5 & 0.060028 \\
\hline 11 & 800 & 88.9 & 50 & 7 & 0.04181 \\
\hline 12 & 800 & 152.4 & 100 & 9 & 0.00126 \\
\hline 13 & 1000 & 47.6 & 5 & 1 & 0.26386 \\
\hline 14 & 1000 & 63.5 & 10 & 5 & 0.00012 \\
\hline 15 & 1000 & 88.9 & 50 & 7 & 0.21345 \\
\hline 16 & 1000 & 152.4 & 100 & 9 & 0.08149 \\
\hline $\begin{array}{c}\text { Aver. } \\
1\end{array}$ & 0.269 & 0.300 & 0.050 & 0.001 & \\
\hline $\begin{array}{c}\text { Aver. } \\
2\end{array}$ & 0.225 & 0.187 & 0.194 & 0.158 & \\
\hline $\begin{array}{c}\text { Aver. } \\
3\end{array}$ & 0.251 & 0.167 & 0.278 & 0.439 & \\
\hline
\end{tabular}




\begin{tabular}{|c|c|c|c|c|c|}
\hline $\begin{array}{c}\text { Aver. } \\
4\end{array}$ & 0.117 & 0.208 & 0.341 & 0.264 & \\
\hline
\end{tabular}

Table 3. Orthogonal design table of reservoir parameters

\begin{tabular}{|c|c|c|c|c|c|}
\hline Factor & $\begin{array}{l}\text { Perme } \\
\text { ability } \\
\text { (md) }\end{array}$ & $\begin{array}{c}\text { Reservoir } \\
\text { thickness } \\
(\mathrm{m})\end{array}$ & $\mathrm{Kv} / \mathrm{kh}$ & $\begin{array}{c}\text { Permea } \\
\text { bility } \\
\text { (md) }\end{array}$ & $\begin{array}{l}\text { The test } \\
\text { results }\end{array}$ \\
\hline 1 & 10 & 10 & 0.1 & 0 & 0.00009 \\
\hline 2 & 10 & 40 & 0.2 & 0.2 & 0.28021 \\
\hline 3 & 10 & 70 & 0.3 & 0.4 & 0.34215 \\
\hline 4 & 10 & 100 & 0.4 & 0.6 & 0.46371 \\
\hline 5 & 50 & 10 & 0.1 & 0 & 0.35262 \\
\hline 6 & 50 & 40 & 0.2 & 0.2 & 0.00034 \\
\hline 7 & 50 & 70 & 0.3 & 0.4 & 0.59514 \\
\hline 8 & 50 & 100 & 0.4 & 0.6 & 0.49931 \\
\hline 9 & 300 & 10 & 0.1 & 0 & 0.49856 \\
\hline 10 & 300 & 40 & 0.2 & 0.2 & 0.63321 \\
\hline 11 & 300 & 70 & 0.3 & 0.4 & 0.01491 \\
\hline 12 & 300 & 100 & 0.4 & 0.6 & 0.35098 \\
\hline 13 & 500 & 40 & 0.2 & 0.2 & 0.66814 \\
\hline 14 & 500 & 70 & 0.3 & 0.4 & 0.49451 \\
\hline 15 & 500 & 100 & 0.4 & 0.6 & 0.33285 \\
\hline 16 & 500 & 10 & 0.1 & 0 & 0.05779 \\
\hline $\begin{array}{c}\text { Aver. } \\
1\end{array}$ & 0.270 & 0.380 & 0.018 & 0.355 & \\
\hline $\begin{array}{c}\text { Aver. } \\
2\end{array}$ & .0357 & 0.350 & 0.327 & 0.363 & \\
\hline $\begin{array}{c}\text { Aver. } \\
3\end{array}$ & 0.374 & 0.316 & 0.459 & 0.354 & \\
\hline $\begin{array}{c}\text { Aver. } \\
4\end{array}$ & .0388 & 0.343 & 0.585 & 0.038 & \\
\hline
\end{tabular}

\section{5 conclusion}

1. The main index to evaluate the effect of ICD water control development is to balance inflow profile and inhibit water production. The influencing factors of ICD completion technology adaptability evaluation are mainly analyzed from inflow, outflow part and inflow control equipment

2. Inflow, outflow and inflow control equipment directly affect the application effect of ICD completion. Geological factors such as reservoir type, reservoir thickness, reservoir heterogeneity, permeability, $\mathrm{kV} / \mathrm{kH}$, and inflow parameters such as horizontal section length, number of segments, and base pipe size are important factors affecting the ICD effect.

3. According to the results of orthogonal analysis, the following conclusions are drawn: the sequence of factors affecting ICD completion adaptability is the number of sections, followed by $\mathrm{PICD} / \mathrm{P} 0$ and horizontal section length, and base pipe diameter is the smallest. Reservoir factors have the greatest impact on the coefficient of variation, followed by average permeability and reservoir thickness, and finally $\mathrm{k}_{\mathrm{V}} / \mathrm{k}_{\mathrm{h}}$. The difference analysis results show that the number of sections and PPICD of reservoir have greater influence on the final result, while the horizontal section length and base pipe diameter have less influence on the final result. Coefficient of variation and average permeability have great influence on the results, while reservoir thickness and $\mathrm{K}_{\mathrm{v}} / \mathrm{k}_{\mathrm{h}}$ have little influence on the results.

\section{References}

1. Saggafmm. Avision for future up stream technologies [J]. Journal of Petroleum Technology, 2008, 60 (3) : 54-98

2. Cui Chuanzhi Xu Jianpeng, Wang Duanping, etal. A new water flooding characteristic curve atultra - high water cut stage $[\mathrm{J}]$. ACTA Petroleum Inica, 2015,36 (10): 1267-1271

3. Du Qinglong. Variation law and microscopic mechanis mofper meability insand stone reservoir during long - term water flooding development [J]. ACTA Petro leis Inica, 2016,37 (9) : 1159-1164.[R]

4. Ou Yang Liang biao Practical consider ation of an inflow control device application for reducing water production. SPE124154, 2009

5. Au Gustine Jr, Mciintyrea Adam, etal. Increasing oil recovery by preventing early waterand gas breakthrough in a west braehorizontal well: acase history [C]. SPE99718, 2006

6. Ebaif Daviesdr, Gaerd Inerar, etal. Evaluation of added value in reservoir management by application of flow control within Telligent wells [J]. Petroleum Geoscience, 2008,14 (2): 183-196

7. Suhui, Donghua Modeling of equalizer production system and smart well application infull - field studies [J]. Spere servoire Valuation \& Engineering, 2009,12 (2): 318-328

8. Sun Kai Guo Boyun, Saputellil. Multinode intelligent well technology for active inflow control inhorizontal wells [J]. Spedeling \& Completion, 2011,26 (3): 386395.

9. Wang Qing, Liu Huiqing Zhang Hongling, etal. Anoptimization model of completion string swith inner - located nozzle in horizontal well scoupled with reservoirs [J]. ACTAPPetroleum Inica, 2011,32 (2): 346-349

10. Yang Jinxian Li Haitao, Dong Shexia, etal. Horizontal well completion optimization with inflow control devices inbottom waterdrive gas reservoirs [J]. Drilling\& ProductionTechnology, 2013,36 (2): 45-47 
11. ZhaoXu, YaoZhiliang, LIUHuanle Technical research on well completion design with inflow control device (ICD) inhorizontalwells [J]. Oil Drilling\&Production Technology, 2013,35 (1): 23-27 